\title{
Using landsat records to detect structures in the ruins of Samarra city - Iraq
}

\author{
Omar B. AL-Jarrah ${ }^{*}$ \\ Applied Geology Department - College of Science - Anbar University - Baghdad - IRAQ
}

ARTICLE INFO

Article history:

Received 25 December 2016

Accepted 05 April 2017

Keywords:

Buried object detection;

High-pass filters;

Image edge analysis;

Landsat.

\begin{abstract}
A B S T R A C T
The ancient city of Samarra represents a distinguished architectural stage in the Abbasid period. Located on the bank of the Tigris River, Samarra was the capital of the Abbasid Caliphate for 58 years (836-892 A.D.) For reasons yet unknown, the city was suddenly abandoned at year 892 A.D., In recent years, everexpanding urban and agricultural areas have threatened to encroach upon the old city owing to its unclear boundaries. Consequently, in 2007, the United Nations Educational, Scientific and Cultural Organization added Samarra to the list of World Heritage sites in danger. It is estimated that approximately $80 \%$ of the city remains unexcavated. The aim of this study was to differentiate between ancient and modern settlements in Samarra using remote sensing methods in order to map the ancient sites. To distinguish the buried structures of the ancient city, Landsat satellite images were enhanced (i.e., change detection and edge analysis) using image processing software. The findings point to the existence of structures that are invisible on the ground surface. These features correspond with irrigation channel systems and other structures found in old maps of Samarra. Human activity threatens to have adverse effects on the ancient city. Determining the boundaries of Samarra will facilitate the development and implementation of protective policies and regulations for this important archeological site.
\end{abstract}

\section{Introduction}

Archaeology is the study of the physical remains of past human societies. Archaeologists study both upstanding monuments (e.g., buildings that are clearly visible) and sub-surface remains (i.e., materials found in the earth that had been gradually buried over time), which are often invisible to the naked eye. Remote sensing technology can not only be used to detect such objects but also to inventory and prioritize surface-level and shallow-depth archeological information in a rapid, accurate, and quantifiable manner ${ }^{[1]}$. The 1920s and 1930s marked a phase of early thinking and theory building on approaches for using surface signatures to locate and analyze subsurface archaeological remains ${ }^{[2]}$, Since then, various archeological tools and methods for remote sensing have been developed, including aerial photography and multispectral scanning [3] Landsat imagery plays a very important role in archeological site searches and, using a sensor known as Thematic Mapper, it can be used to identify various land features, such as surface tracks ${ }^{[4]}$.

\footnotetext{
* Corresponding author.

E-mail address: oaljarrah@yahoo.com
}

\section{Materials and methods \\ The Physical Theory of Remains Reflectance}

Spectral signatures, captured using remote sensors, are used to identify different physical features and materials. Satellite sensors with sufficiently high spatial resolution can capture the spectrum of sunlight reflected by the surface of the earth ${ }^{[5]}$, This spectrum provides information about land surface composition and patterns, including those indicating past human activities and structures, such the distribution of houses, drainage systems and road networks ${ }^{[3]}$.

Remote sensing archaeology explores cultural relics using space-borne images as well as ground surveys. The overlying soil on these relics is distinct from surrounding soils in color, texture, humidity, and compactness, especially when the farming soil layer has been ploughed. Such differences affect the absorption and reflection of solar radiance and thermal radiation from objects. Remote sensing technology can perceive the spectral characteristics of objects on the ground surface and those a short distance beneath the surface $(1-2 \mathrm{~m})^{[6]}$, Rough data are used to build models of buried or underground sites and artifacts. This type of predictive model building depends on the characteristics of the 
reflectance waves.

Buried features can be identified by visual interpretation and analysis of the colors, tones, and textures in an image ,Some polygonal features and a paleo river ramification, structures are characterized by brighter grey tones or darker colors in some image processing software ERDAS [5].

\section{History of Samarra}

In 2007, the city of Samarra was officially named a World Heritage Site. Samarra is located approximately $130 \mathrm{~km}$ north of Baghdad (Fig. 1) and was once the capital of the Abbasid Empire ${ }^{[7]}$. In 836 A.D, Caliph Al-Mu'tasim moved the caliphate's Turkish and Armenian slave soldiers (known as the Mamluk), out of Baghdad (then, the capital city) to Samarra, which eventually became the center of government for 58 years until 892 A.D, when Baghdad was reinstituted as the capital. Over the years, several caliphs (e.g., Al-Mu'tamid, Al-Mu'tasim, and Al-Wathiq) contributed to the development of Samarra's commerce although many of the most notable achievements to this end occurred under Caliph Al-Mutawakkil ${ }^{[8]}$.

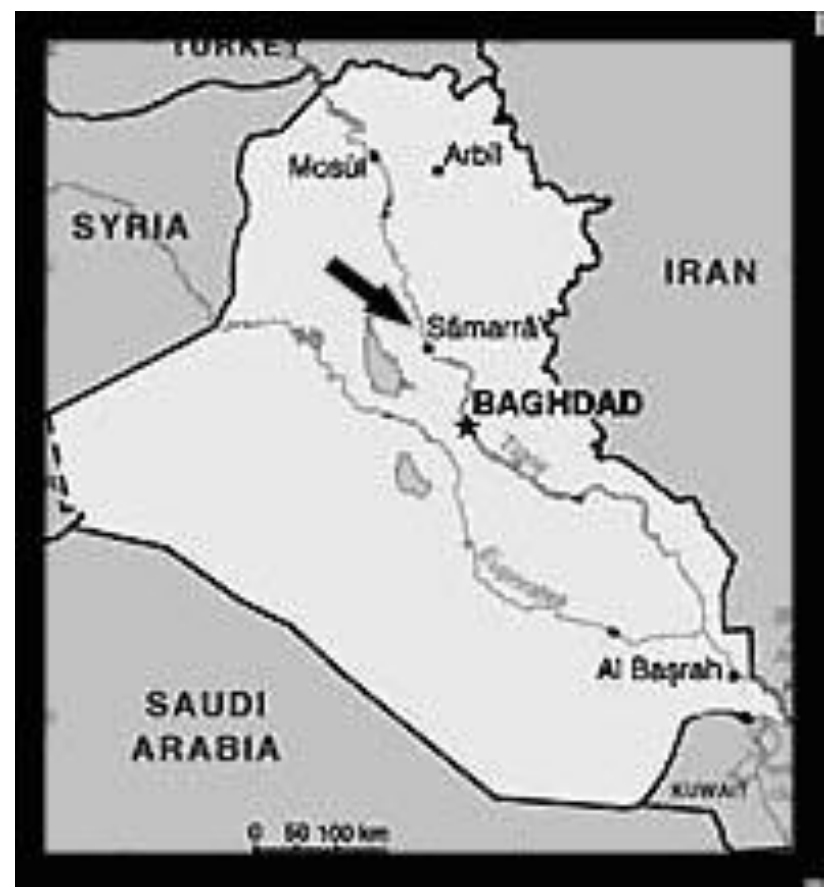

Fig (1): Regional map

Samarra represented a peak of architectural achievement for the Abbasid Empire. The city was designed to incorporate many kinds of public and social spaces (e.g., public gardens, a horse track, a large mosque and irrigation channels); however, most of those structures were destroyed or buried over time, except for some ruins that remain exposed ${ }^{[9]}$.

It remains a mystery why this city was suddenly abandoned with the effect of natural threat come from shifting and changing of the river course, and make Samarra best preserved plan of an ancient city ${ }^{[7]}$.

\section{Irrigation System of Ancient Samarra}

For years, the people of Samarra used animals to carry water from the river for daily use, or they dug wells, which produced poor-quality, salty water As the city grew, these methods proved to be insufficient. The solution then was to dig a network of open and underground channels to transport fresh water from the Tigris River, north of Samarra, to main locations in the city. These channels formed a complex system, some of which still exists today ${ }^{[10]}$, However, the Tigris was prone to flooding; consequently, the natural and artificial channels that once irrigated the forests, gardens and agricultural fields of Samarra became covered with sediments from the Tigris floods.

\section{Detection of Old Channels and Structures}

Using the results from remote sensing, archaeologists can pinpoint which parts of a site to excavate, rather than excavating an entire site ${ }^{[11]}$, The materials used in Samarra buildings included gypsum, mud, coarse gravels, fire brick and mud brick, Climatic factors majorly affected these materials, and they continue to have an impact on the archaeological site. Recent climatic anomalies (i.e., climatic change) have resulted in stronger winds and heavier rains than had previously existed in the region. Additionally, while rain is destroying adobe constructions, dust storms are severely affecting archaeological monuments, covering great parts of them ${ }^{[7,12]}$.

Timely archeological exploration of Samarra is, therefore, very important, and $80 \%$ of the city has yet to be excavated.. Because the structures and channels of Samarra were built using materials that are generally similar to the contents of the soil in the surrounding area, the satellite-recorded reflectance signatures of those objects are difficult to distinguish. Thus, image processing, particularly edge enhancement, is required to detect buried features by making high level of constructing to short wave bands (some more penetrate ability to the land surface). The Sobel operator performs a 2-D spatial gradient measurement on an image and so emphasizes regions of high spatial frequency that correspond to edges. Typically it is used to find the approximate absolute gradient magnitude at each point in an input grayscale image. the operator calculates the gradient of the image intensity at each point, giving the direction of the largest possible increase from light to dark and the rate of change in that direction the operator consists of a pair of $3 \times 3$ convolution kernels ${ }^{[13]}$ (Fig. 2) .

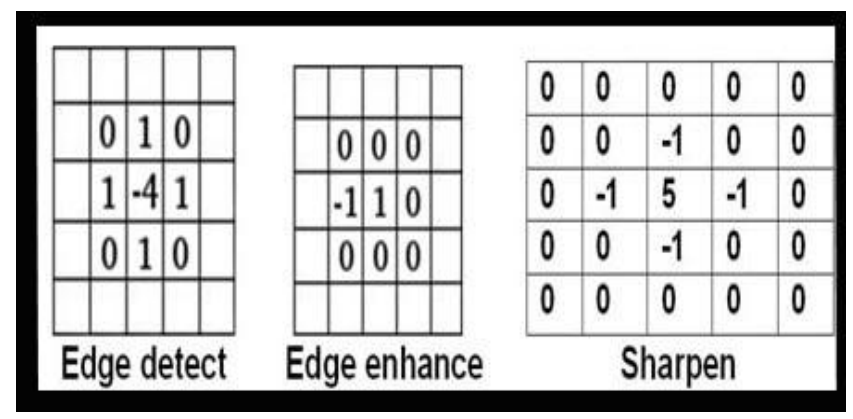

Fig (2): Sobel filters used 
In this study, we chose six sites in the Samarra area by applying Sobel filters and using archival maps. We approximately matched the processed Landsat satellite ETM+ images (resolution 15 m) dated 16 Apr 2000 with the maps to estimate the locations of the six sites.

\section{Results}

Site 1 - The four circles: Circular tracks were used during the Abbasid period for military parades and, occasionally, sports events. Figure 3 shows an aerial photo taken in 1938 depicting four similar-sized circles grouped together in the left panel. Using satellite images and edge enhancement, a more recent image of the site was obtained in 2000 (Fig. 3, right panel). The image shows that only one of circles (No. 3) is still recognizable; no new villages developed near this circle.
By contrast, two of the circles (No. 2 and 4) were extremely affected by recent human activities, including the development of buildings, farming, and digging of irrigation channels. One circle (No. 1) appears to have entirely disappeared due to the same reasons.

Site $\mathbf{2}$-Heer (Nature Reserve): Figure 4 shows images of Heer, a large (approximately $30 \mathrm{Km}^{2}$ ) nature reserve built by Al-Mu'tasim with high walls to prevent animals from escaping. Al-Mu'tasim oversaw the digging of the Naizek River, which carried water from the Nahrawan channel in the north to the Tigris River in the south. The river was used for irrigation inside the Heer area ${ }^{[14]}$, Currently, the original walls of the Heer enclosure and the long-since buried Naizek River can be partially, but clearly, detected using processed satellite images, enhanced with edge detection (Fig. 4).

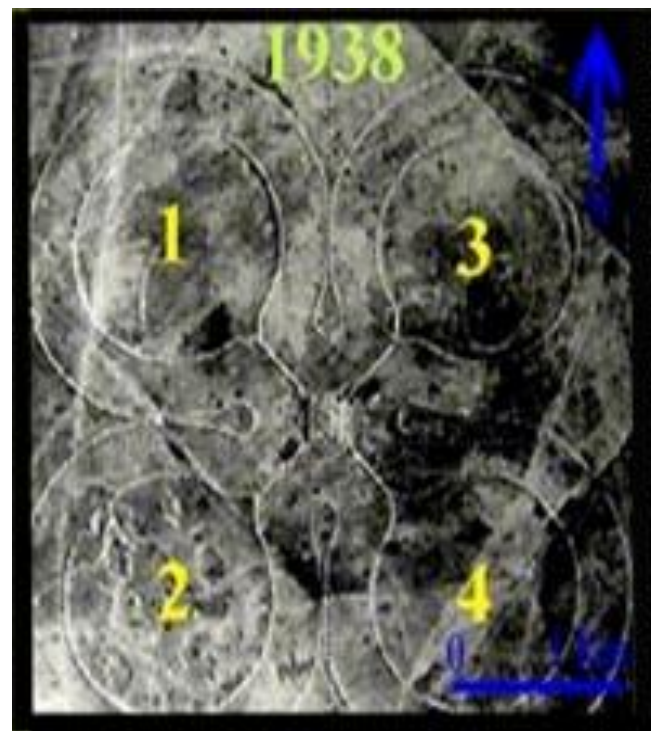

Areal Photo 1938

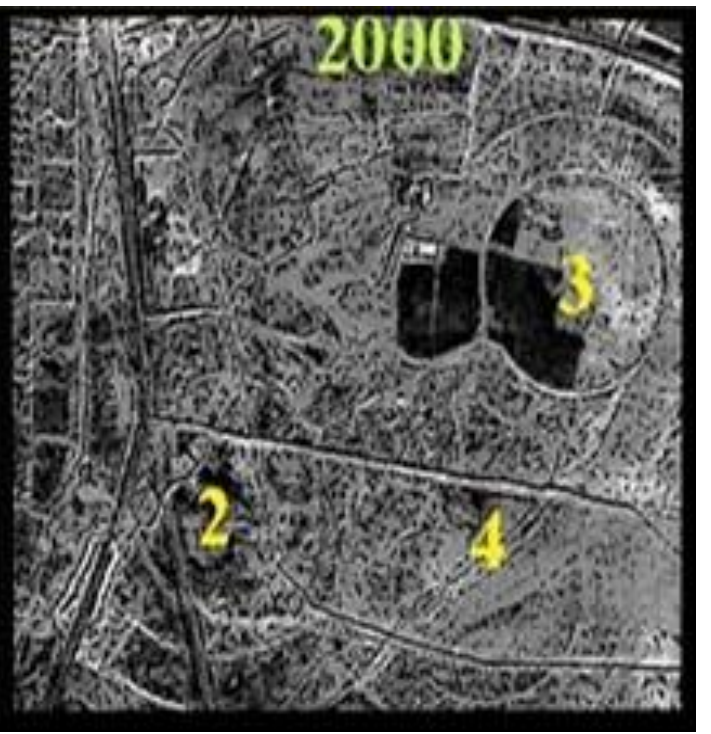

Satellite Image 2000

Fig (3): Changes at the four track circles

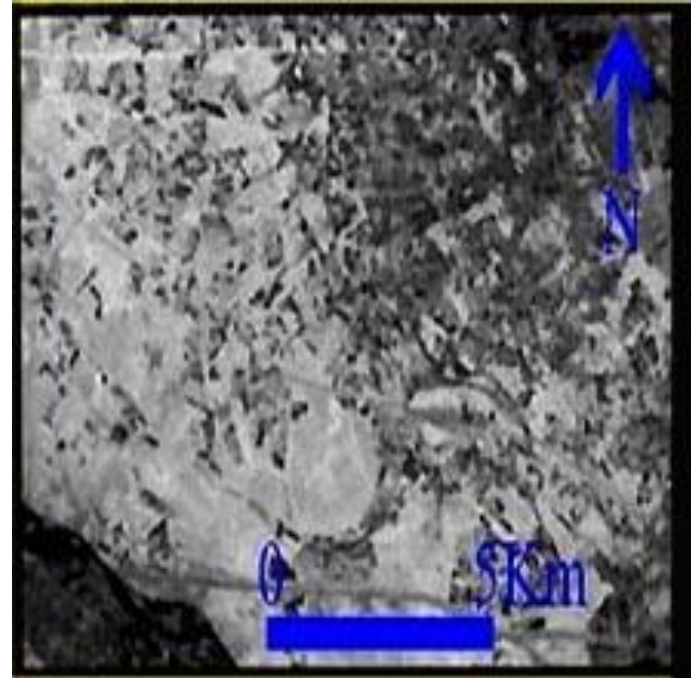

Before Filtering

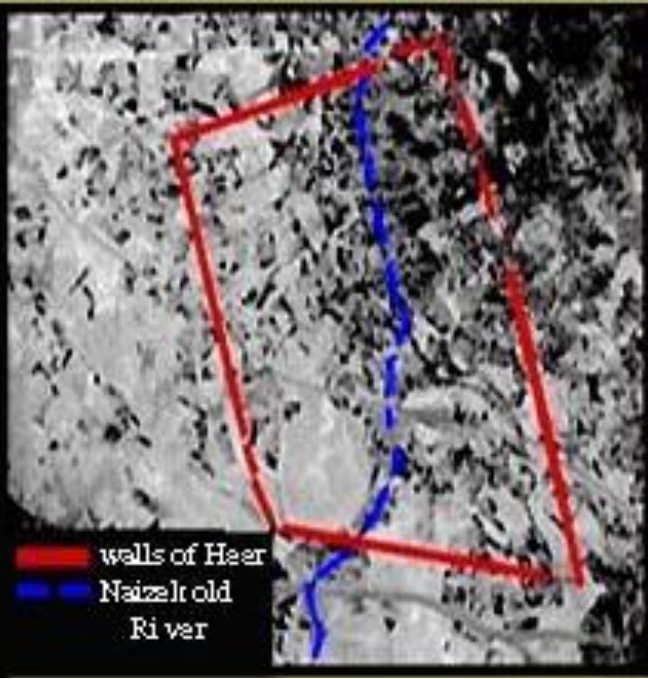

After filtering

Fig (4): Heer (Nature Reserve) and Naizek River 
Site 3 - Horse racing track: Several historical references mention the existence of a horses racing track in Samarra ${ }^{[14]}$. Even though the area is now being used for agricultural purposes, we can detect the traces of the elliptical racing track using Sobel filters on the edges of the track. The structures that once surrounded the track (e.g., the horse stables) appear with highly sharpened edges (Fig. 5).
Site 4 - Al-Qadisya Barbican: One of outer defense castles, known as Al-Qadisya, was octagon shaped and featured large gates and numerous facilities, including living quarters for officers and soldiers, administrative buildings, and military stores, also the existence of fresh water channels as well as a drainage system. These features are no longer visible aboveground; however, Sobel filters were used to identify the buildings and channels with high level of clarity (Fig. 6).

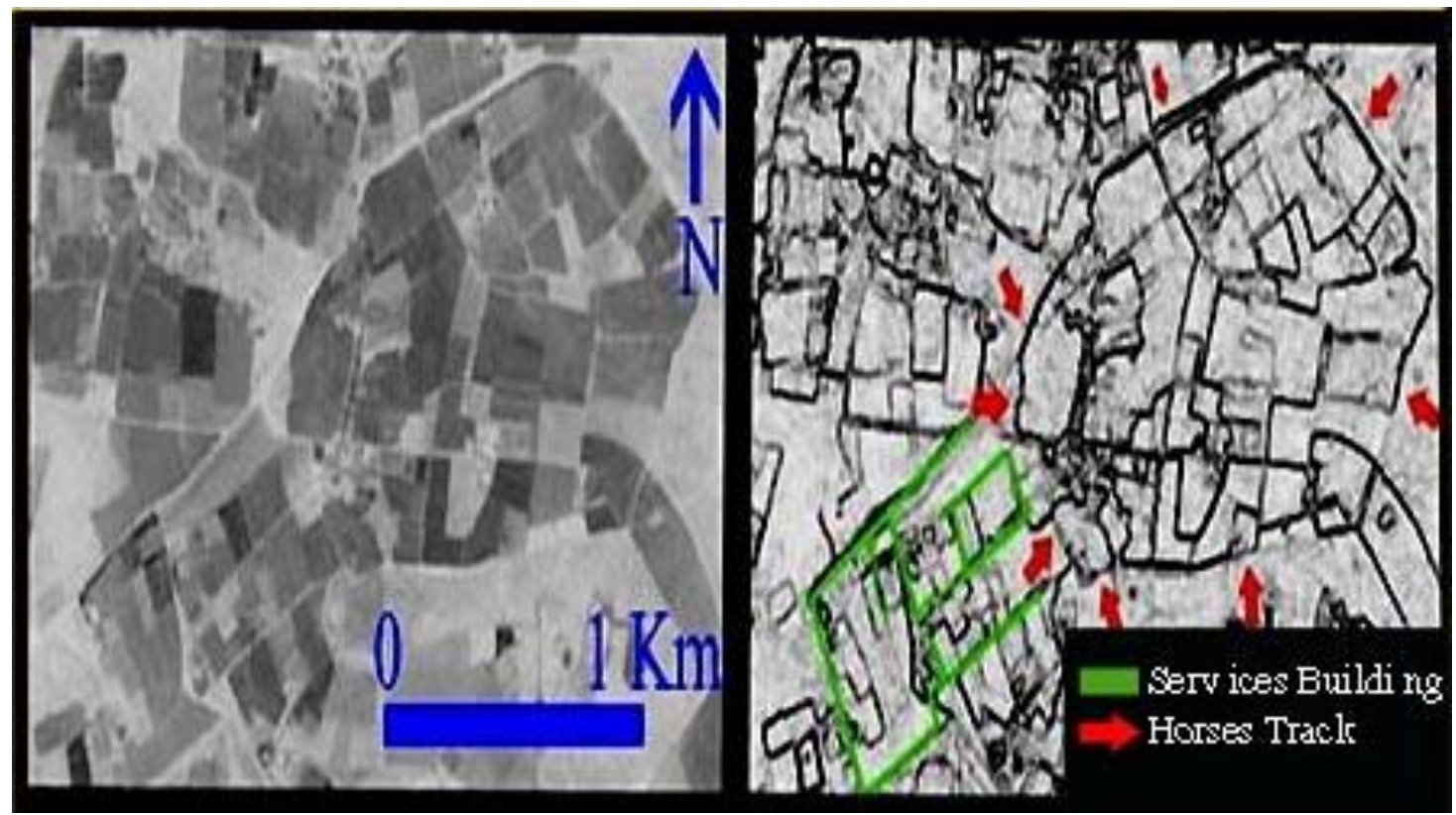

Before Filtering
After filtering

Fig (5): Horses race circle with services buildings

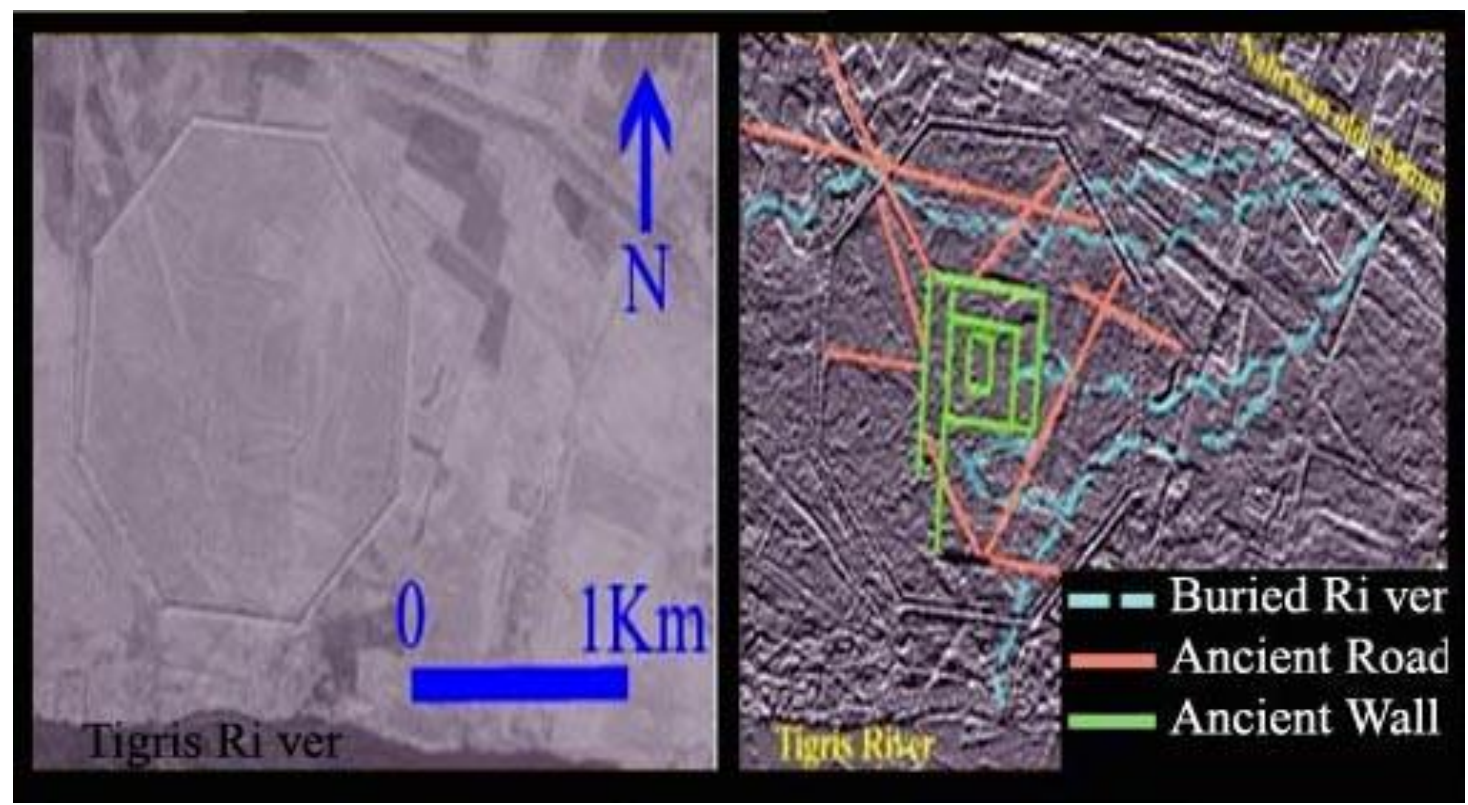

Before Filtering

After filtering

Fig (6): Al-Qadisya Barbican 
Site 5 -Heer Palace: At the south wall of the Heer area stood Heer Palace, which featured a large artificial Lake called Al Buhtary. The palace was used as a resting place for the caliph when he visited the lake. The palace and lake were supplied with fresh water from the Naizek River that passed through the Heer nature reserve. Application of Sobel filters showed the boundaries of the palace and the Naizek river (Fig. 7).

Site 6 - Nahrawan Irrigation Channel: The Nahrawan is one of most important historical artificial irrigation channels dug in the $6^{\text {th }}$ century. The channel started from the east bank of the Tigris (north of Samarra) and continued south past Baghdad toward Kut (south Iraq)

${ }^{[15]}$.The main purpose of this channel was to supply the groves and gardens along its banks with fresh water from the Tigris, especially those in Baghdad. The channel was also used as a military defense line against invasions from the east. In the $10^{\text {th }}$ century, this channel was ignored because of the economic troubles and invasions . Presently, many parts of the channel are completely covered with sediments, while others became very shallow. New channels and buildings (e.g., residential buildings and bridges) have been built over the Nahrawan, making it difficult to recognize the old channel in a land survey. By applying digital filters (i.e., Sobel filter and edge enhancement) to satellite images of the area, we could identify the original course of the Nahrawan (Fig. 8).

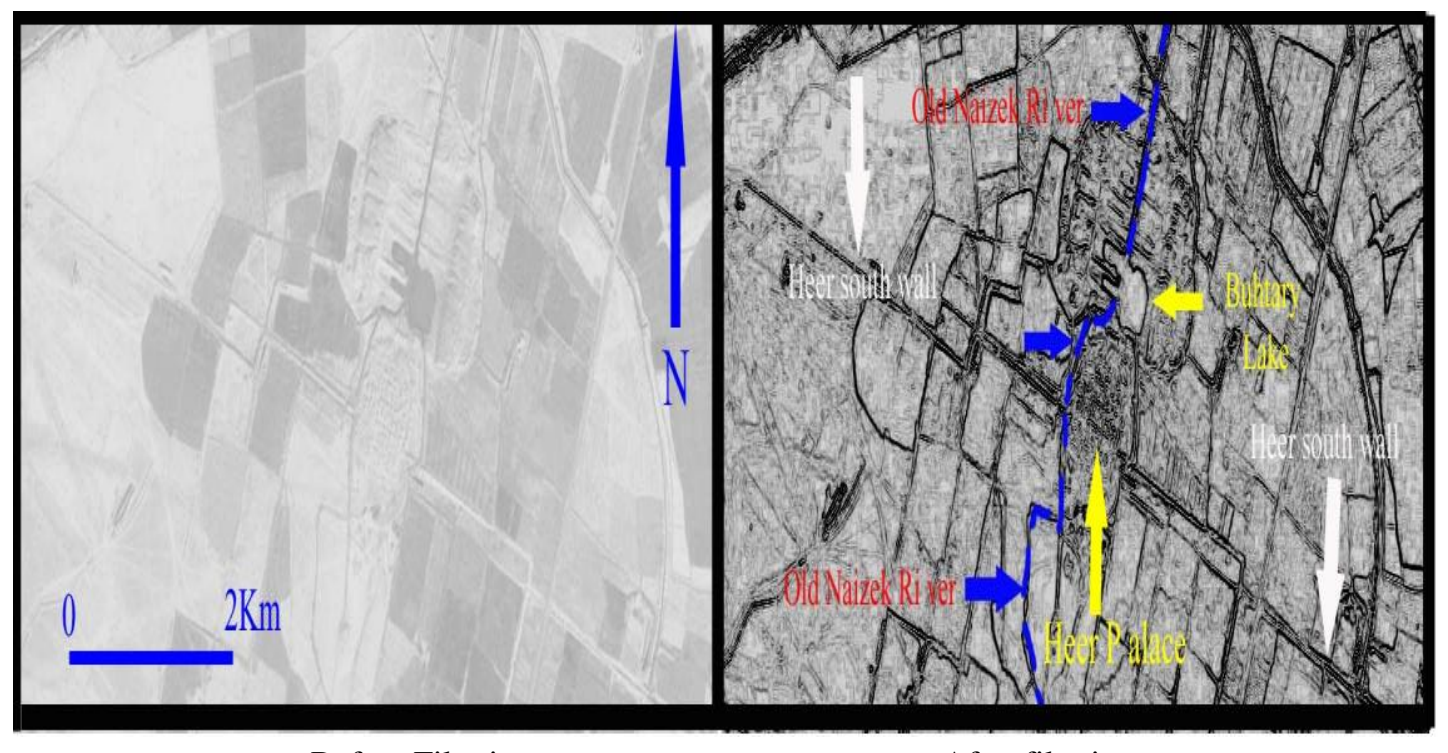

Before Filtering

After filtering

Fig (7): Heer Palace

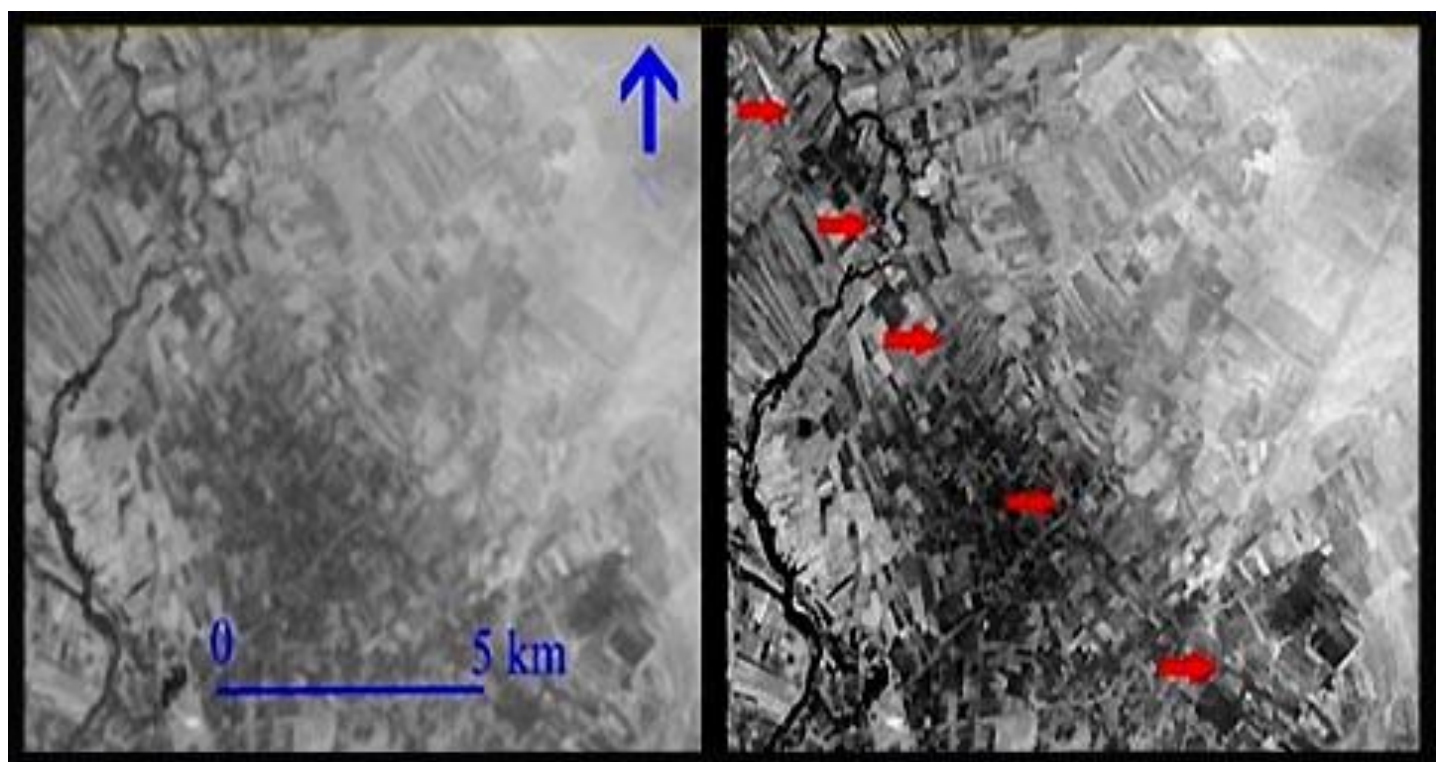

Before Filtering

After filtering

Fig (8): Nahrawan irrigation channel 


\section{Discussion}

There are many other notable sites in Samarra, including several palaces, public residences, mosques, and government offices. Although archaeological researchers and groups have been exploring the area for many decades, no new details could be found; however, because approximately $80 \%$ of the city has yet to be excavated, Samarra warrants further study and exploration.

Remote Sensing techniques and satellite imaging have proven effective at identifying buildings and structures, which are mostly invisible in field surveys, despite the lack of reflectance variation due to the similar components found in building materials at Samarra city and the surrounding soil. Using satellite recording with high bandwidth reflectance and digital filter image processing, we can detect details in the ruins and adjacent areas. Many historical sites in Samarra have been damaged or have completely disappeared because of looting, lack of oversight and farming activity near the sites. Such activities must cease in order to preserve this World Heritage Site.

Further satellite imaging and processing must be done to detect buried features of Samarra to support future field work.

\section{References}

1) Smoot, J. L. (2007). Archeology, NASA MSFC Earth science office. The scopt report for social science selection.

2) Bevan, A. (2011). Landscape through a LensAeral Photographs and historic Environment, John wily \& Sons Ltd, P 428.

3) Hadjimitsis, D. j., Agapiou, A., Themistocelous, K., alexakis, D. and sarris, A. (2013). Remote sensing for archaeological application: Management, documentation and monitoring, book edited by Diofantos G. Hadjimitsis, ISBN 978-95351-1152-8, Published: July 10, 2013 under CC BY 3.0 license. (C) The Author(s).
4) Omaninfo.com. (2016). How remote sensing helped find a lost city of Ubar, Oman information center, People and society Articles.

5) Trampier, J. (2009). Ancient towns and New methods: A GIS remote sensing-guided, archaeological survey in the western Nile Delta, JDHCS 1(1), The Division of the Humanities at the University of Chicago, :1 - 6 .

6) Kelong, T., Yuqing, W., Lin, Y., Riping, Z. and Yaobao, M. (2008). A new archaeological remote sensing technology. Proc. The International Archives of the Photogrammetry, Remote Sensing and Spatial Information Sciences, 37:221-224.

7) Raouf, S. M. and Francesco, S. (2010). Samarra archaeological city monitoring, UNESCO, P15.

8) UNESCO. (2013). 37COM 7A.25-SAMARRA Archaeological City (Iraq) (c276rev.).

9) Abd, F. N. (1984). Project of maintenance to Samarra and Matawakelya ancient cities, SUMER, Vol. XLIII(1-2): 30-49.

10) Hamdy, K. H. (1982). Mutasim Palace at Samarra, SUMER, 38(1-2):168-175.

11) Sanderland, P. (2012). The role of remote sensing in archaeology, Helium, Inc. Helium.com: A Service of RR Donnelley.

12) AL-Rawi, S. A. (1982). Study about conservancy of the walls and Islamic building at Samarra, SUMER, 38(1-2):206-210.

13) Sobel Operator. (2016). Wikipedia, the free encyclopedia.

14) Sosa, A. (1948). Samarra irrigation at Abbasid period, Maref press, Part1, P.284.

15) Kennedy, H. (2004). The prophet and the age of the caliphates: The Islamic Near East from the $6^{\text {th }}$ to the $11^{\text {th }}$ century (Second Edition), Edinburgh, pearson, Education Ltd, ISBN 0-582-40-525-4. 